\title{
Wedging War Against Corruption in Nigeria Using Transformation Agenda as a Weapon: The Way Forward
}

\author{
Blessing .E.N Thom-Otuya \\ Department of Political Science \\ Ignatius Ajuru University of Education \\ Port- Harcourt, Nigeria
}

\section{Doi:10.5901/mjss.2013.v4n5p129}

\begin{abstract}
Many scholars have written on corruption in Nigeria. Their observations and recommendations have hit a brick wall of no effect. Many government programmes on change have failed in one way or the other due to corruption. In this dispensation, President Goodluck Jonathan has put in place a Transformation Agenda that is aimed at transforming the Nigerian economy to meet the future needs of Nigerians and hit a prominent economic position by 2020 in world arena. This paper is pessimistic on the success of the Transformation Agenda in midst of pervasive corruption in the system. This paper hold the view that for the transformation agenda to be successful, it must have a strong focus on mitigating corruption as a sine qua non in achieving the purpose of the transformation agenda. This paper is aimed at using the Transformation Agenda as a weapon to wedge war against corruption in Nigeria. Corruption prevention education. Re-orientation programme is recommended to detune the pervasiveness of corruption, strengthening the Judiciary for independent and effective performance, aspiring political office holders should be screened by the State Security Services and Independent National Electoral Commission, and severe punishment for offenders is recommended as the way out of stamping corruption; which this paper hold as a precondition for the success of the Transformation Agenda.
\end{abstract}

\section{Introduction}

Corruption is an ancient and global phenomenon that has defied all institutional remedy in Nigeria. Oladimeji, and Onabajo (2008) traced the origin of corruption to the period of Adam and Eve when they were confronted by the serpent. Lipset and Lenz (2000) also traced corruption to ancient Egypt, Rome and Greece, thus emphasizing the fact that it is not of recent origin.

In their study on corruption, Yusuf and Saka (2008) also observed that, more developed countries are less corrupt than less developed or developing countries as a result of the differences in their income and welfare condition which are determinant of the level of corruption. They stressed that where income is equitably distributed, there seems to be less incidence of corruption than where there is a high degree of inequality in income distribution.

The 1996 revelation on corruption by Transparency International and Goettingen University ranked Nigeria as the most corrupt Nation, among 54 nations listed in the investigation with Pakistan as the second highest (Moore, 1997). In the corruption perception Index Nigeria was ranked 75 out of the 81 countries pooled. In the year 2001 through Corruption Perception Index (CPI), the image of Nigeria slipped further down. This placed Nigeria 90 out of 91 countries pooled, making Nigeria the second most corrupt nation. In 2003, when Bangladesh came first, Nigeria still remained in second position i.e. 132 out of 133 countries.

Government in Nigeria has responded to the problem of corruption by implementing one programme or the other, and these include: the Ethical Revolution, National Re-orientation, War against Indiscipline, Mass Mobilization for Self-Reliance and Economic Recovery (MAMSER), War against Indiscipline and Corruption. 
Despite all these efforts by various regimes to find solution to the problem of corruption, corruption seems to be defiling all curative measures put in place by the government (Johnson 2009).

These failed policies provoked the then President Olusegun Obasanjo to declare war against corruption when he came to power in 1999. He created legal institutions, such as: Independent Corrupt Practices and other related offences Commission (ICPC) and the Economic and Financial Crimes Commission (EFCC) to combat corruption in Nigeria. Inspite of these institutional creations, corrupt practices were very glaring during the regime of President Obasanjo.

In this dispensation, the administration of President Goodluck Jonathan has initiated a Transformation Agenda. This is a holistic transformation of the Nigerian State. It set up priority policies and programmes which when implemented will transform the Nigerian Economy to meet the future needs of the Nigerian people and, to hit a prominent economic position by 2020 in world arena. This paper is focused on how to use the Transformation Agenda to fight corruption in Nigeria. It discussed the concept of corruption, Transformation, Classification of corruption, Causes of corruption, effects of corruption on the transformation of Nigeria and how to wedge war against corruption.

The study is aimed at strengthening the crusade against corruption, reduce corruption, and facilitate the success of the Transformation Agenda to elevate Nigeria economy by 2020 in the world arena.

\section{Clarification of Concepts}

Corruption: Has no universal meaning. Different scholars have viewed corruption differently. The Webster's New Collegiate Dictionary (1974) define corruption as "impairment of integrity, virtue or moral principles" World Bank (2000) defines corruption as "the abuse of public office through the instrumentality of private agents who actively offer bribe to circumvent public policies, and process of competitive advantage and profit. World Bank (1997) also referred to corruption as abuse of power for the purpose of obtaining a benefit whether monetary or otherwise. Corruption, according to Nye (1976) is "deviation from the formal duties of a public role because of close family, private clique, pecuniary exercises of certain types of private influence. This includes such behaviour as bribery (use of reward to pervert the judgment of a person in position of trust), nepotism appointment by reason of inscriptive relationship rather than merit, and misappropriation, illegal appropriation of public resources for private uses. Olurode (2000) said, corruption has come to be universally defined as the giving of an inducement so as to act in an illegitimate way or in order to refuse to act as desired by law.

Brooks (1974) defined corruption as the institutional mis-performance or neglect of a recognized duty, or the unwarranted exercise of power, with the motive of gaining some advantage more or less directly personal. Nikolich (2003) sees it as the misuse of public power for private gains Alatas (1990) characterized corruption as the abuse of trust for the sake of private benefit. However, in this paper, corruption will refer to the abuse and compromise of one's position and trust for personal gain.

Transformation, according to the Oxford Advanced Learner's Dictionary( $7^{\text {th }}$ edition) means complete change in appearance or character of something. The Transformation Agenda refers to strengthening government institutions to facilitate effective coordination of fiscal monetary policies and for effective and optimal performance. In this paper transformation refer to complete change and re-orientation of corruption value system and the strengthening of the three arms of government, government institutions and the Nigeria economy for national development.

\section{Classification of Corruption}

Yusuf and Saka (2008) Classified Corruption as:

Institutional Corruption: This is corrupt action or policy within an Organization. 
Political Corruption:this occur when policy formulation and legislation is tailored to benefit politician and legislators. It is equally a situation when government official, political official employees, seek illegitimate personal gain through actions such as bribery, extortion, cronyism, nepotism, patronage, graft and embezzlement.

Moral corruption: this has to do with immorality and indiscriminate acquisition of women, examination malpractices, nepotism.

Financial corruption: Worldwide emphasis on corruption is centered on financial corruption and it's ascribing debilitating effect on economic development of the poor nation of the world. This act is perpetrated through bribery, illegal and greedy acquisition of public funds into private pocket, which otherwise would have been invested for the public goods.

In Nigeria, the corrupt practices and other related offences Act, 2000, outlined twenty items that constitute corruption. They are:

* Offence of accepting gratification.

* Offence of giving or accepting gratification through agent.

* Acceptor or giver of gratification to be guilty notwithstanding that purpose was not carried out or matter not in relation to principal affair or business.

* Counseling offences relating to corruption.

* Fraudulent acquisition of property.

* Postal offences and penalty of offences committed through the postal system.

* Deliberate frustration of investigation by the commission.

* Making false statement or return.

* Gratification by and through agents and defilation of agent.

* Bribery of public officer.

* Using office or position for gratification.

* Bribery in relation to auctions.

* Bribery for giving assistance etc with regard to contracts.

* Failure in the duty to report bribery transactions.

* Dealing with property acquired through gratification.

* Making false or misleading statements to the commission.

* Attempted/actual criminal conspiracy as a punishable offence.

* Evidence of corroboration.

* Misappropriation or mis-use of funds and other resources contrary to their original purposes.

\section{Causes of Corruption}

Bresson in Yusuf and Saka (2008) suggested five economic condition which appear to encourage the flourishing of corruption within a society. These are:

- The existence of an exploitable natural resource (e.g. oil) providing the opportunity for state authority, both administrative and political to obtain payments.

- The general scarcity of public assets relative to demand, accompanied by policies of fixed official prices which create opportunity for informal rationing through bribery.

- Low wages in the public sector are also likely to be associated with extensive low level corruption payment.

- High level of state intervention/planning (i.e. protectionism, state owned enterprises, price controls, exchange controls, import licenses etc) which has characterized many developing countries.

- Economies in transition are likely to have particular problems as they undertake privatization and establish the relevant legal framework of company and contract law etc.

- Other causes of corruption, as outlined by Oladimeji and Onabajo (2008) are: 
- The political system and the culture of a society.

- Great inequality in distribution of wealth, political office as the primary means of gaining access to wealth.

- The weakness of social and governmental enforcement mechanism.

- The absence of a strong sense of national community.

- Lack of ethnic standard throughout the agencies of government and business organization.

- Societal influence - people in the society usually tell the people in authority that, it is their time to make money in their life because of the position they find themselves.

- Luke-warm attitude of those who are supposed to enforce the laws of the land (judges, police officers and public officials) could lead to encouragement on the part of those who engage in corrupt practices because they will go scot-free.

- Poor reward system and greed.

\section{Essentials of the Transformation Agenda}

The transformation agenda is the articulation of government prioritized policies, programmes and projects that will guide President Goodluck Jonathan's administration from 2011 to 2015. It articulates Nigeria's development efforts characterized by continuity, consistency and commitment popularly referred to as the $3 \mathrm{cs}$. The transformation agenda is challenged by the rising unemployment, inequality and poverty. The programme is a response to a holistic transformation of the Nigerian state. If the programme is properly implemented, it will transform the Nigerian Economy to meet the future needs of the Nigerian people and, meet her expectation of being among the top twenty economies in 2020 (The Transformation Agenda 20112015 summary of Federal Government's key priority policies programmes and projects).

The transformation agenda is poised to strengthened and facilitate effective coordination of fiscal and monetary policies, job creation, public expenditure management, maximize the benefit the citizenry derives from good governance through more effective and efficient use of public resources, proper financial management and fiscal prudence. Improve the justice and judiciary pace of investigations and potent enforcement of judicial decision. Improve our foreign Policy and Economic diplomacy by focusing and funding our foreign mission properly. Improve the legislature for optimal and proactive performance.

Priority policies on Human Capital Development programmes and projects. The programme articulated that:

Human Capital Development is strategic to the socio-economic development of a nation and includes education, health, labour and employment and women affairs. Investing in human capital development is therefore critical as it is targeted at ensuring that the ration's human resource endowment is knowledgeable, skilled, productive and healthy to enable the optimal exploitation and utilization of other resources to engender growth and development. (The Transformation Agenda 2011-2015 summary of Federal Government's key priority policies programmes and projects).

Here attention is given to priority policies for the development of Education, Health sector, labour and productivity.

The following seven sectors have been identified as the main growth drivers during the transformation period. They are agriculture and food security, water resources, solid minerals, manufacturing, oil and gas, trade and commerce as well as culture and tourisms (The Transformations Agenda). The challenges of these sectors are: low productivity, low level of private sector investment, non-competitiveness, inadequate funding, shortage of skilled manpower, low investment in research and development, poor development of value chain and low value addition, poor regulatory environment, poor quality of goods and services and poor state of physical infrastructure, policy instability and discontinuity, low level of technology, paucity and poor flow of information and high cost of doing business. 
During the programme period, the following key priority policies will be pursued to develop infrastructure and consequently engender sustained growth and development in the country. They are: priority policies for infrastructure development - power, information and Communication Technology, Niger Delta, Transportation.

Monitoring and Evaluation (M\&E) is an assented component of programme implementation. It is a veritable tool for tracking development in policy and programme performance. The Nigerian vision 20:2020 and the 1' ${ }^{\text {st }}$ ational Implementation Plan 2011-2013 provided a comprehensive framework for M and E. The next challenge is capacity to implement the design.

\section{Effect Corruption on the Transformation of Nigeria}

Corruption is largely a function of political culture (Johnson, 2009). The Nigerian political culture encourages corruption hence; there is great need to transform our public sector and economy to be corrupt free. Political corruption is manifested in elections and succession, and the manipulation of people and institutions in order to retain power and office. Political positions are scarce and the prizes of political office are high. The competition for such resource position involves every possible extra legal means through corruption in order to overcome obstacle and opposition. Politics in Nigeria is an investment where the investors are set to make profit at all cost, as a result, political corruption is pervading the society. The transformation agenda does not make any provision of restructuring the political culture. The transformation programme ought to have started transforming the source of the economic problem which is corruption. The Nigerian economy cannot be meaningfully transformed without transforming the political system.

Corruption is equally part of Nigerian social value system. I mentioned earlier in this paper, how friends and relation will be telling political office holders that, "this is your time to make it i.e., this is your time to use your position to steal, divert or over invoice and employ your relatives. The people as a matter of the social value system encourage their brothers and friends in position of trust to be corrupt. This false value system has to be transformed before, the economy can be transformed. General Burhari and Idiagbon, tried it during their short stay in office by proclaiming "War against indiscipline". Their programme was successful but short lived hence could not bring about change in the system. An ethical transformation will precede an economic transformation in Nigeria. Therefore, the transformation programme of President Goodluck Jonathan will have less positive impact in the Nigerian society, until a comprehensive transformation that involve ethical reorientation is embarked upon.

The transformation agenda is geared towards the economic transformation of the country. Corruption is an obstacle that will undermine economic development in Nigeria by generating considerable distortion and inefficiency. Will the transformation programme stop bureaucrats from collecting illicit payment from investors that want to invest in Nigeria? If the answer is no, how can investors take advantage of the transformation agenda, when bribes and kickbacks will inflate the cost of investment is Nigeria. Corruption therefore shields private investors and firms from investing and from competition and thereby sustaining inefficient firms. Corruption causes retardation of economic growth, lowers investment which leads to low economic growth and development. It also brings about low quality of infrastructures and public services.

Corruption promotes unemployment in that it deprives the qualified persons who could not afford to pay bribe from securing jobs and unqualified persons who are able to bribe their way out are given such jobs. Increased unemployment breeds increase in crime.

Adeoti (2006) posited that corruption impoverishes countries and deprives their citizens of good governance and can slow down development rather than be beneficial. It destabilizes economic systems while organized crime and other illegal activities flourish. Corruption erodes basic public functions and the quality of life of people. Bribery is, for example, universally regarded as a crime, but it also reflects socioeconomic problems that require broad-based preventive measures, and the involvement of society at large. 
One of the most widely discussed consequences of corruption on political and economic wellbeing according to Ayua (2001), is the distortion of governmental expenditures caused by corruption. This, according to him, often results in public money being spent on large-scale projects, typically military or infrastructure projects, rather than on the necessary public services such as; health and education. The rationale behind this is that with large-scale expensive projects, more opportunities are presented for corrupt use or diversion of the funds.

\section{Wedging War against Corruption: The Way Forward}

The transformation agenda can adopt these measures to wedge war against corruption. They are:

- Corruption Prevention Education: should be introduced at all level of education. Considering the extent of corruption in Nigeria, the immorality of corruption, its negative effects to the society and its punishment should be thought in schools.

- Re-orientation Programme: the pervasiveness of corruption in Nigeria is quite alarming; it has permeated all the economic and social sectors. It is now a culture of a people. Changing or reversing this culture requires a re-orientation programme for every Nigerian; every establishment should talk against corruption as a safety pep talk on weekly basis. This re-orientation will gradually change our perception and involvement on corruption. The National Orientation Agency, religious organizations and various non-government organization can be used for this campaign against corruption in the society.

- Strengthening the Judiciary for independent and effective performance: duplication of institutions to fight corruption will not help to wedge war against corruption. The Economic \& Financial Crime Commission (EFCC) and the Independent Corrupt Practices Commission (ICPC) should be scrapped. In midst of pervasive corruption, when you duplicate functions that create conflict of work between government agencies, you give room for more corrupt practices due to lack of commitment to duty. The Judiciary should be strengthened for independent and effective performance, a special department comprising the operatives of State Security Services and Judiciary staff should be constituted to handle cases of corrupt practices; with a special Court to be presided by a Justice attached to it.

More Lawyers should be recruited into the judiciary for efficient and timely dispensation of justice in all her departments. Political office contenders should be required to face public debates on how to handle the challenges of their offices, so that voters can appraise their skills and propensity to perform if voted into power.

- Aspiring Political Office Contenders should be screened by the operatives of State Security Services and Independent National Election Commission or an independent body selected for the purpose without serious attachment to political parties in truth.

- Severe punishment for offenders: considering the pervasiveness of corruption in Nigeria, the deterrence antidote to corruption is not effective. Severe punishment should be meted on culprit. Government should build more comfortable prison yards all over the federation. Short prison term should be prescribed for corruption offenders without option of fine. By the time big men are deprived of their freedom for one year, most persons will be afraid to commit the crime of corruption.

\section{Conclusion}

This paper observed that several scholars have written enough against corruption in Nigeria, their recommendations have not reduced the pervasiveness of corruption. Several regimes too have put in place 
one anti corruption programme or the order, yet corruption seems to be defiling all curative measures put in place by the governments.

The transformation programme of President Goodluck Jonathan is a welcome policy and programmes. It is intended to overhaul and advance the economy of Nigeria. The programme has corruption as the greatest challenge to its success. The fight against corruption remains one of the greatest challenges for Nigerian Leaders. It is an evil that is capable of derailing the transformation programme. The transformation programme should not only focus at the transformation of the institution of governance and the economy alone, but should focus more on reducing corruption. If this is not done, the transformation programme will go to the grave yard to join her counterparts.

The battle against corruption is not the responsibilities of government alone. The Social sector, Cultural, Education and Religious institutions should be agent of re-orientation programmes. Various Social organizations should preach against corruption, corruption prevention education should be introduced at all levels of institutional learning's.

The paper equally recommended corruption prevention education, re-orientation programme that will be led by National Orientation Agency, which will mobilize the social, cultural, educational, religious and other non-governmental organizations to carry out the re-orientation programme, this will detune the pervasiveness of corruption. In addition, strengthening the Judiciary for independent and effective performance, aspiring political office holders should be screened by the State Security Services and Independent National Electoral Commission agents, and severe punishment for offenders should is recommended as the way out of corruption and, enhancing the success of the Transformation Agenda.

However, if the recommendations herein are followed with strong political will, the transformation agenda will wedge a strong war against corruption, and strengthen the institutions and economic sector for the advancement of the Nigerian economy and her people.

This paper will serve as a pathfinder for other impact assessment studies on various aspects of the Transformation Agenda.

\section{References}

Adeoti, G.O. (2006). Corruption in Nigeria society and the role of the church in its eradication. Paper Presented at the Conference of Theological Education held at Nigerian Baptist Theological Seminary, Ogbomogho $8^{\text {th }}$-10 ${ }^{\text {th }}$ March.

Alatas, H.S. (1990). Corruption: Its nature causes and functions. Kuala Lumpur: S. Abdul Majeed.

Ayua, I. (2001) Proceedings of the National Conference on the Problems of Corruption in Nigeria, 26-29 March 2011, Abuja.

Brooks, R.C. (1974) Corruption in American Politics and Life. New York, Arno Press.

Hornby, A. S., (2005). Oxford advanced learner's dictionary, $7^{\text {th }}$ Edition, Oxford, Oxford University Press.

Johnson, A.U. (2009) The Socio-economic and political reforms in Nigeria: the Role of Corruption in policy Failure. Society and Development. An Interdisciplinary Journal of the Nigeria Sociological Society,

Lipset and Gabriel (2000) Corruption, Culture, and Markets, Lawrence E. Harrison, and Samuel P. Huutington (eds) culture Malters New York Basic Books.

Moore, E. (1997) Power and Corruption. City Vision Paper Book.

Nikolech, R. (2003). Corruption, Prevention and Education. International experienced and recommendations. Retrieve from www.absolukok.com.

Nye J.S. (1967) Corruption and Political Development: A Cost Benefit Analysis. American Political Science Review, Vol. Lx (2).

Oladimeji, M.S. \& Onabajo, A.M. (2008) Corruption in Nigeria and its nexus to Economic Development. Pp286-300

Olorode, L. (2005). The Blurring of the threshold and the Metamorphosis of the debasement of Public life (paper presented at the 2005 public lecture of the Chartered institute of Administration, Airport Hotel Ikeja 25 October.

Webster's New Collegiate Dictionary (1980) G \& C Merriam Company, Spring Field Mass USA.

World Bank (2002) Helping countries combat corruption.

Yususu, M.O. and Saka, J.O. (2008) Culture of Corruption: An Assessment of the Effects on human and Economic Development in Nigeria.pp 276-285 
